\title{
Ação Formativa e o Desafio para a Graduação em Saúde
}

\author{
The Challenge of Undergraduate Education \\ in the Health Professions
}

Sílvia Maria Nóbrega-Therrien ${ }^{I}$ Laura Martins Feitosa

PALAVRAS-CHAVE

- Graduação.

- Ensino.

- Pesquisa.

\section{KEY-WORDS}

- Graduation.

- Teaching.

- Research.

Recebido em: 13/09/2008

Reencaminhado em: 03/03/2009

Reencaminhado em: 21/08/2009

Aprovado em: 26/08/2009

\section{ABSTRACT}

This study aimed to identify and characterize, in the health curriculum policy proposals at the State University of Ceara (UECE), the strategies used to organize the curriculum, interrelating and integrating teaching and research. Sources included the curriculum policy proposals from the various courses and prevailing Brazilian national legislation for higher education. There are a total of 16 disciplines in Research Methodology: 5 in Nursing, 4 each in Biology and Physical Education; 2 in Nutrition; and 1 in Medicine. Physical Education was the only course that provided a continuous supply of disciplines throughout undergraduate training. The course syllabi showed a concentration of technical information in introductory disciplines during the early semesters and applied disciplines during the subsequent semesters. Positive changes were observed, like the implementation of a discipline for writing the course monograph. However, the requirement of teaching scientific methodology and the course monograph are not sufficient to integrate research into teaching. There is a need for curricular adjustments and on-going evaluation of the curriculum policy proposals. 


\section{INTRODUÇÃO}

A educação superior no Brasil está sendo convocada para demonstrar qualidade e eficácia ${ }^{1}$. O novo profissional deve estar capacitado para os desafios que a prática exige e preparado na pesquisa para buscar respostas às indagações advindas dessa prática. Fica clara, assim, a relevância que atribuímos a desenvolver o ensino articulado à pesquisa, que se torna, aqui, o objeto central do nosso estudo. As respostas a parte dos questionamentos registrados ao longo dessa argumentação resultaram no objetivo central deste trabalho, que visa evidenciar e caracterizar, nos Projetos Político-Pedagógicos (PPPs) dos cursos de graduação da área da saúde da Universidade Estadual do Ceará (Uece), a estruturação dos componentes do contexto de formação profissional que contribuem para a ação formativa numa perspectiva que relacione e integre ensino e pesquisa.

\section{PESQUISA COMO PRINCÍPIO FORMATIVO}

Os papéis primordiais da universidade são, ao lado da transmissão, a geração de conhecimentos, ao proporcionar um espaço institucional de questionamento e a formação de recursos humanos com o fim de responder às necessidades da sociedade que a mantém ${ }^{2,3}$. Na era da informática e das telecomunicações, na qual as informações circulam muito rapidamente, gerando dispersão e superficialidade de dados e raciocínio, a reorganização e a produção das ciências impõem repensar a dinâmica do conhecimento em seu sentido mais amplo $^{4,5}$. Surgem novos olhares e possibilidades de compreensão do que significa educar o homem: diferentes campos da ciência, distintos contextos geopolíticos e múltiplas realidades sociais indicam a necessidade de investir em práticas educacionais que tenham na participação crítico-reflexiva ${ }^{6}$ um pilar fundamental.

Possuindo três instâncias fundamentais - assistência, ensino e investigação - , as universidades privilegiam muito mais o aparelho formador de recursos humanos, abandonando sua dimensão crítica e reflexiva ${ }^{2}$. Esta assimetria de prioridades conduz à visão linear que acaba interferindo na formação superior atual. Nesse panorama, situam-se desafios e perspectivas na graduação, no caso, dos profissionais de saúde - campo interdisciplinar que materializa diferentes níveis de compreensão e intervenção junto aos sujeitos a serem formados.

Em 1986, Gonçalves7 já afirmava que “[...] o nosso estudante de graduação é menos um participante e cada vez mais um mero observador"(p. 22). Em anos recentes, observamos frequentemente uma concepção empirista de ensino, na qual existe uma desarticulação entre teoria e prática, e passividade por parte do aluno ${ }^{8}$. Nota-se que a grande maioria das disciplinas ainda utiliza um método de repasse de conhecimento, privilegiando apenas a memorização, numa visão "armazenativa" da inteligência. Confunde-se conhecimento com informação memorizada, e inteligência com um processo acumulativo de inputs. Esta maneira mecânica de utilizar informações faz com que grande parte do que se ensina não seja retida para ser posteriormente reconduzida nos contextos ou situações que vão surgindo. Nesse sentido, o aluno vai descobrindo "novos" conhecimentos, dissociados dos conhecimentos antes recebidos, sem envolvimento, tanto prático como críticoreflexivo.

A opção hegemônica pela valorização da formação técnica, principalmente nos cursos da área da saúde, sobretudo no de Medicina, substitui o modelo crítico e baseado na reflexãona-ação ${ }^{9}$ por um modelo de formação instrumental, que facilita a desconexão entre leitura e escrita, realidade e fazer profissional, pesquisa-ensino-aprendizagem ${ }^{8}$. Demo ${ }^{10}$ trouxe conceitos transformadores para esta realidade ao dizer que: "O profissional não é aquele que apenas executa sua profissão, mas sobretudo quem sabe pensar e refazer sua profissão" (p. 68). Ainda nos diz o autor: "[...] não se pode gestar o profissional competente pela via do treinamento, em particular escutando aula e fazendo prova" (p.69); e conclui o pensamento dizendo: "[...] somente profissionais conscientes, questionadores, atualizados, participativos, reconstrutivos podem construir para renovar a profissão e dar conta dos sempre novos desafios" (p. 70). Tais afirmações exemplificam as ideias que serviram de base para a elaboração dos novos programas educacionais ${ }^{11}$.

Entendemos que as mudanças no ensino superior se tornarão viáveis e aceleradas se os educadores reformularem sua visão do processo de ensino e de aprendizagem, dando ênfase ao desenvolvimento efetivo do espírito crítico, isto é, se permitirem ao aluno desenvolver sua capacidade de analisar, avaliar, questionar, investigar, divergir, argumentar e experimentar ${ }^{12}$. Acreditamos que um caminho viável para alcançar este processo seja uma interação maior entre ensino e pesquisa nos currículos universitários e, mais pontualmente, no ambiente da sala de aula, o que implica não apenas alterações curriculares, mas também a formação docente. O diálogo com a literatura e com essa experiência formativa, por meio do trabalho docente com os alunos de graduação, permite reconhecer a possibilidade de configuração de práticas educativas que lidem com a diversidade, pluralidade e complexidade, promovendo uma racionalidade emancipatória ${ }^{13,14}$, por intermédio do ensino com pesquisa.

Acrescentamos ainda a preocupação com a formação dos alunos da área de saúde no intuito de levá-los a uma consci- 
ência enquanto cidadãos e futuros profissionais conhecedores de uma realidade mais ampla, que emerge do conhecimento histórico da sua profissão e também das influências dos sistemas de infraestrutura e superestrutura sobre esta ${ }^{15}$. Acreditamos que a maneira mais acessível de viabilizar esse processo de mudança seja por meio dos PPPs dos cursos de graduação. Tal reflexão converge para os questionamentos que fazemos: que tipo de formação é pretendida e com qual finalidade? Como a universidade pode formar indivíduos com postura crítico-reflexiva que implica a necessidade de uma relação constante entre ensino e pesquisa? Como se atinge este objetivo?

Esses "nós" críticos traduzem desafios para construir propostas formativas em saúde, sinalizando a relevância de que os professores construam um saber sobre o enfoque de articulação entre ensino e pesquisa por meio de atividades investigativas com seus alunos. Esta temática (propostas formativas em saúde) vem sendo abordada, discutida e aprimorada ao longo dos anos por meio de encontros, congressos e publicações em educação superior das sociedades de ensino em saúde — Associação Brasileira de Ensino Médico (Abem), Associação Brasileira de Ensino de Biologia (SEBnBIO), Diretoria de Educação da Associação Brasileira de Enfermagem (ABEn), Comissão de Educação do Conselho Federal de Educação Física (Confef) e Associação Brasileira de Nutrição (Asbran) -, e em conferências universitárias internas que buscam a avaliação e constante (re)construção curricular, demonstrando empenho e avanço em direção a uma nova realidade. Ainda há, contudo, uma grade ausência de análises e estudos sobre a aplicação e vivência dos currículos e da pedagogia universitários na literatura educacional nacional.

Logo, às já citadas preocupações, agrega-se o risco de tomar o enfoque científico, o qual defendemos, como simples instrumento técnico, vinculado à matriz curricular por meio do PPP, mas afastado do chão da sala de aula.

Por esta razão, é fundamental a manutenção de esforços no processo de formação de sujeitos envolvidos com a pesquisa desde o ciclo básico: alunos em contato direto com o pensamento e o fazer científico, envolvidos com a prática da reflexão e da crítica nas salas de aula.

Assim, esta pesquisa pretende descrever e analisar a relação entre ensino e pesquisa no contexto e na prática dos Projetos Político-Pedagógicos (PPPs) dos cursos de graduação da área da saúde da Universidade Estadual do Ceará, tendo como referenciais elementos de uma epistemologia da prática que fundamentam a compreensão do profissional reflexivo e a reflexão na e para a ação como fatores de competência e de formação para a produção do conhecimento.

\section{METODOLOGIA}

O método da pesquisa baseou-se na análise documental e na revisão e enriquecimento dos dados coletados com a utilização das falas dos coordenadores de cada curso da área da saúde pesquisado, coletadas por meio de entrevistas semiestruturadas. Dos documentos analisados, destacam-se os PPPs, vigentes no ano de 2007, dos cinco cursos de graduação do Centro de Ciências da Saúde (CCS) da Uece: Medicina, Enfermagem, Nutrição, Ciências Biológicas e Educação Física. Dos cursos avaliados, obtivemos os conteúdos curriculares, ementas das disciplinas e enfoque dado à pesquisa no perfil do egresso, uma vez que procurávamos evidenciar a existência da pesquisa como atividade proposta nestes cursos. Além destes, analisamos as orientações contidas nos documentos do Ministério da Educação sobre o processo de reforma da educação superior no Brasil, Lei de Diretrizes e Bases da Educação Nacional, 1996'1 Diretrizes Curriculares Nacionais de Graduação dos Cursos da Área de Saúde, $2003^{16}$ e Pró-Saúde, $2005^{17}$.

Nessa análise, alguns pontos não eram esclarecidos, bem como surgiam questionamentos sobre a supressão/inserção de elementos no currículo. Em cada ponto em que isso acontecia, formulávamos perguntas que, posteriormente, vieram compor o instrumento de entrevista com o qual nos orientamos ao abordar os coordenadores dos cursos pesquisados. Assim, nosso instrumento de coleta de dados foi um construto particularizado para cada interlocutor, visando aclarar dúvidas específicas que surgiram da análise documental. Contudo, ressaltamos que, no estudo aqui apresentado, essas entrevistas funcionaram apenas como suporte para compreensão da realidade estudada e não como foco ou objeto de estudo. A análise dessas entrevistas e da concepção apresentada pelas coordenações sobre o ensino da pesquisa e sobre o ensino com pesquisa compõe outro eixo de um estudo maior, ainda em processo de conclusão.

Os dados obtidos a partir da análise documental foram expostos em quadros de forma a facilitar a análise comparativa entre os cursos e a compreensão da realidade de cada um destes, visto que possuem processos históricos de criação e concepção de perfil profissional distintos, o que sugere também um estudo separado a ser feito posteriormente.

Por vezes, os objetivos dos cursos de graduação, definidos em seus PPPs, não são mais do que a expressão de intenções nem sempre realizadas. Umas das formas de avaliar, indiretamente, o quanto tais intenções se traduzem na prática é uma atenta análise do currículo. Logo, na composição deste trabalho, não pretendemos apenas criar um desenho das grades curriculares e classificá-las como possuidoras ou não de disciplinas com ensino da pesquisa, pois acreditamos que esta 
seria uma contribuição limitada, ainda que para reflexões iniciais. Buscamos, por meio da leitura das ementas e de todo o texto dos PPPs, verificar a integração da pesquisa ao processo de ensino como um princípio formativo e não somente como um princípio científico ${ }^{18}$. Todavia, como fruto da metodologia aplicada, nosso estudo restringiu-se ao âmbito descritivo. Portanto, a evidência da concretização em sala de aula dos resultados por nós alcançados e a existência de mecanismos alheios aos PPPs em prol da integração ensino-pesquisa não se prestam como objetivo deste trabalho.

A pesquisa faz parte do projeto maior, Saberes profissionais: um estudo sobre a formação e atuação dos profissionais de saúde enquanto sujeitos reflexivos, submetido ao Comitê de Ética em Pesquisa da Uece, obedecendo, portanto, à Resolução 196/96 e tendo sido aprovada sob o Parecer n ${ }^{\circ}$ 04185965-0.

\section{RESULTADOS, ANÁLISE E DISCUSSÃO DOS DADOS COLETADOS}

O currículo é a expressão formal do projeto pedagógico de um curso e deve representar a realidade diária desse curso para além dos aspectos teóricos formalizados num texto oficial. É interessante perceber o currículo em sua função integradora, no sentido de que pode aproximar fundamentos e práticas; atualizadora, podendo constituir objeto de reavaliações desses fundamentos e práticas; e estruturante, ao permitir a articulação e consolidação da constituição e das perspectivas acadêmicas dos cursos ${ }^{2}$. Analisaremos, então, os currículos dos cursos investigados.

As disciplinas obrigatórias direcionadas para o ensino da pesquisa nos cursos de saúde da Uece estão divididas entre disciplinas introdutórias e disciplinas de orientação para preparo de monografia (Quadro 1). O curso de Enfermagem, que passou por uma reforma e implantou um novo currículo a partir do primeiro semestre de 2005, não demonstrou diferenças em número de disciplinas de pesquisa apresentadas e carga horária entre seus dois currículos atualmente em voga (dados de julho de 2007). Apresentou diferença apenas no semestre de oferta da primeira disciplina de pesquisa do curso.

As disciplinas estão divididas em introdutórias e conclusivas (Quadro 1). Pela leitura das ementas, pode-se constatar melhor esta sequência. Notamos um caráter mais teórico nas primeiras, que se encarregam de fornecer aos alunos de graduação os elementos básicos da investigação e as fases do projeto de pesquisa, de forma que o aluno passe a deter conhecimentos sobre a metodologia científica e normas de produção de pesquisa, o que não exclui exercícios práticos em seu desenvolvimento. Um caráter prioritariamente prático fica mais reservado ao segundo grupo de disciplinas. Esse grupo é responsável pelo desenvolvimento, por parte dos alunos, do Projeto de Monografia, que inclui a aplicação das normas do trabalho científico (redação científica), desenvolvimento dos procedimentos metodológicos e elaboração de quadro teórico.

Dencker $^{19}$, ao estudar pesquisa e interdisciplinaridade no ensino superior na área de turismo, relata constatação semelhante à nossa: no primeiro grupo de disciplinas, são realizados estudos de natureza exploratória, pesquisa bibliográfica e observação controlada pelos alunos. A elaboração de projetos de pesquisa, construção de instrumentos de coleta, iniciação nas técnicas de análise quantitativa dos dados e interpretação dos resultados são o foco do segundo grupo de disciplinas. Observamos, entretanto, que não há uma divisão rigorosa dessa sequência em nosso estudo, pois o curso de Medicina, que tem uma só disciplina de pesquisa em sua grade curricular, apresenta uma ementa de disciplina mais abrangente, não obedecendo à divisão de conteúdos proposta nos currículos dos cursos de Enfermagem, Educação Física, Ciências Biológicas e Nutrição.

Outra caracterização das disciplinas introdutórias de metodologia é apresentada por Luckesi et al. ${ }^{20}$. Para os autores, o conteúdo programático destas disciplinas “[...] não é apenas um amontoado de técnicas, embora elas devam existir e tenham um papel" (p. 27). No entendimento desses autores, a Metodologia do Trabalho Científico "[...] deve estar sempre em relacionamento e a serviço de uma proposta de universidade e de profissional que se quer construir e para a qual nos voltamos" (p. 27). E acrescentam: "Sem essa proposta de universidade e, consequentemente, de curso, o 'que-fazer' de metodologia se torna estéril, sem definição, ilusoriamente neutro" (p. 27). E concluem: "Por conseguinte, ao encarar disciplinas de metodologia, estamos diante de uma disciplina instrumental, a serviço explícito de um determinado tipo de universidade" (p. 27).

Fica clara na análise dos autores a postura também ética e política da própria universidade ou curso que seguem em uma direção ou em outra. A abordagem também é pontual quando se detêm na análise das disciplinas, mais precisamente caminhando na compreensão de que pesquisa só se aprende pesquisando. Essa posição é percebida quando Luckesi et al. ${ }^{20}$, com relação às disciplinas conclusivas, referem:

[...] a tônica do curso deve ser aquela de "fazer com as mãos". Isto é, praticar. Não basta apenas verbalizar e reter informações ou mesmo discuti-las. É preciso fazer. Tratando-se de uma disciplina instrumental, acreditamos que de pouco ou nada adiantaria fazer os alunos "assimilarem" mais algumas informações. A nosso ver, 
Quadro 1

Disciplinas obrigatórias de pesquisa com suas cargas horárias e semestres de oferta nos cursos do CCS da Uece (julho de 2007)

\begin{tabular}{|c|c|c|c|}
\hline Curso & Disciplinas obrigatórias & $\begin{array}{l}\text { Carga } \\
\text { horária }\end{array}$ & Semestre \\
\hline \multirow{3}{*}{$\begin{array}{c}\text { Enfermagem } \\
97.1\end{array}$} & Metodologia da Pesquisa em Enfermagem & $60 \mathrm{~h}$ & $3^{\mathrm{o}}$ \\
\hline & Monografia & $30 \mathrm{~h}$ & $8^{\mathrm{o}}$ \\
\hline & Monografia & $30 \mathrm{~h}$ & $9^{\mathrm{o}}$ \\
\hline \multirow{3}{*}{$\begin{array}{c}\text { Enfermagem } \\
2005.1\end{array}$} & Metodologia da Pesquisa em Enfermagem & $60 \mathrm{~h}$ & $2^{\underline{o}}$ \\
\hline & Monografia I & $30 \mathrm{~h}$ & $8^{\mathrm{o}}$ \\
\hline & Monografia II & $30 \mathrm{~h}$ & $9^{\mathrm{o}}$ \\
\hline \multirow{3}{*}{$\begin{array}{l}\text { Educação } \\
\text { Física }\end{array}$} & Métodos e Técnicas de Pesquisa & $60 \mathrm{~h}$ & $4^{\mathrm{o}}$ \\
\hline & Metodologia da Pesquisa em Educação Física e Esportes & $60 \mathrm{~h}$ & $6^{\mathrm{o}}$ \\
\hline & Monografia I & $60 \mathrm{~h}$ & $7^{\mathrm{o}}$ \\
\hline \multirow{2}{*}{ Nutrição } & Metodologia do Trabalho e Pesquisa Científica & $30 \mathrm{~h}$ & $1^{\mathrm{o}}$ \\
\hline & Monografia & $30 \mathrm{~h}$ & $9^{\circ}$ \\
\hline Medicina & Métodos de Estudo e Pesquisa & $72 \mathrm{~h}$ & $1^{\mathrm{o}}$ \\
\hline \multirow{4}{*}{$\begin{array}{c}\text { Ciências Biológicas } \\
\text { (diurno) }\end{array}$} & Métodos em Biologia & $60 \mathrm{~h}$ & $1^{\mathrm{o}}$ \\
\hline & Metodologia da Pesquisa I & $30 \mathrm{~h}$ & $5^{\mathrm{o}}$ \\
\hline & Metodologia da Pesquisa II & $30 \mathrm{~h}$ & $7^{\mathrm{o}}$ \\
\hline & Trabalho de Conclusão do Curso - Monografia & $360 \mathrm{~h}$ & $7^{\mathrm{o}}$ \\
\hline
\end{tabular}

deste modo, eles não estariam capacitados metodologicamente para fazer a universidade que propomos. Saberiam apenas repetir informações. Por isso, a tônica deve ser fazer com as mãos. A leitura crítica, a monografia, a documentação têm que ser efetivamente praticadas e, assim, efetivamente, aprendidas. (p. 28)

Autores como Dencker ${ }^{19}$ e Luckesi et al. ${ }^{20}$, entre outros, contribuem com a compreensão de que a teoria é uma explicitação refletida e analisada da prática. A teoria tem na prática sua origem e a ela deve voltar, de forma que esse processo não deve ser interrompido. A constante relação entre teoria e prática é condição sine qua non para a existência da pesquisa.

Percebemos, ainda no Quadro 1, que a nomenclatura utilizada para denominar as disciplinas é semelhante nos cinco cursos. O caráter obrigatório dessas disciplinas é extremamente importante para oficializar, mesmo que por meio de uma mínima existência, a integração entre ensino e pesquisa na universidade, embora não assegure o desenvolvimento dos domínios necessários à produção do trabalho cientifico.

Notamos, entretanto, que mesmo as disciplinas de pesquisa dos cursos estudados se encontram alheias ao contexto de integração e interdisciplinaridade, uma vez que até seus conteúdos programáticos se apresentam de maneira fragmentada, o que explicita a existência dessas disciplinas mais como um cumprimento da legislação vigente (LDB/96 e DCN/2003) do que como a concretização de um novo modelo de ensino-aprendizagem. Os movimentos para as transformações curriculares, quando se limitam aos textos escritos e a reorganizar a carga horária, desconhecendo o impacto de outros fatores, que constituem partes determinantes daquele conteúdo, limitam as possibilidades de inovação. Desta maneira, corre-se o risco de limitar a pesquisa a sua noção técnica simplesmente e não ligá-la à construção permanente do conhecimento a partir da prática, de modo a formar profissionais reflexivos. Isto se torna relevante porque, em geral, nos processos de reforma curricular, tem-se partido do pressuposto de que, inserindo os alunos numa nova ordem de disciplinas, necessariamente eles se sensibilizarão para uma nova postura como profissionais. Esta percepção de que o aprendizado é passivo, de que basta expor o aluno a um novo contexto curricular que ele irá absorver é um caminho que pode levar ao insucesso dessas propostas inovadoras ${ }^{8}$. 
A formação profissional depende, além do padrão curricular, de critérios de natureza pedagógica, política, social e econômica. É preciso que haja uma sólida aprendizagem educacional, que, ademais, precisa ser mantida e atualizada. Os currículos, geralmente, são apontados como os grandes vilões da baixa qualidade no ensino superior. No entanto, essa situação está muito relacionada com falhas na formação dos professores universitários. Desta forma, a citada fragmentação dos conteúdos programáticos, observada nas ementas das disciplinas, demonstra a presença de um corpo docente constituído por professores que, mesmos titulados com mestrado ou doutorado, muitas vezes não possuem competências como educadores, quanto à área pedagógica e à perspectiva político-social, o que pode comprometer o desenvolvimento de projetos educacionais. A necessidade de formação educacional permanente dos docentes é hoje reconhecida não só nos programas inovadores, mas também naqueles tradicionais de alto nível ${ }^{21}$.

As cargas horárias individuais das disciplinas introdutórias de pesquisa também são semelhantes entre si. Para as disciplinas divididas em estágios I e II, temos, na soma de suas cargas horárias, uma constante entre a maioria dos cursos. $\mathrm{O}$ curso de Educação Física apresenta maior tempo disponível para as disciplinas divididas por etapas. Quanto à carga horária disponível para o preparo da monografia, o curso de Ciências Biológicas possui um número de horas mais elevado que os demais. De acordo com a coordenadora do curso, profa. MS. Germana Costa Paixão, este fato se deve a uma distribuição diferente dos horários da disciplina, o que incluiria estágios, aulas teóricas e orientação para a monografia por professores. Ainda segundo a coordenadora, essa proposta de ensino se baseia na tentativa de alcançar as metas expressas na LDB/96 contempladas pelas Diretrizes Curriculares do curso de Ciências Biológicas para o implemento do ensino da pesquisa no curso.

Em artigo publicado na Revista Latino-Americana de Enfermagem, Cassiani et al. ${ }^{22}$ (p. 80), utilizando a Técnica de Delphi, constataram que a disciplina de Metodologia da Pesquisa para os cursos de graduação sugeria a carga horária de 60 horas ou, no caso de haver mais de uma disciplina, que cada uma dispusesse de 45 horas. Tais valores são baseados na análise da opinião de diversos profissionais docentes da área, que responderam a questionários elaborados pelas autoras em seu estudo. No texto das autoras, tal carga horária se refere apenas às chamadas disciplinas introdutórias, não contemplando disciplinas de elaboração de monografia.

Desta forma, observamos que quase todos os cursos identificados se enquadram nesse perfil. A exceção é o curso de Nutrição, que tem apenas uma disciplina introdutória de pes- quisa, perfazendo um total de somente 30 horas, metade do sugerido pelos docentes envolvidos na pesquisa de Cassiani et al. ${ }^{22}$. Em outras palavras, nesse entendimento, o ensino da pesquisa nos cursos de Ciências Biológicas, Educação Física, Enfermagem e Medicina da Uece contempla, com a sua carga horária exigida, o mínimo necessário à aprendizagem do aluno em pesquisa. Nos cursos de graduação, a carga horária pode ser conquista e manifestação de prestígio e poder. A disputa histórica pelo prestígio e poder está exibida no currículo: a presença de umas e a ausência de outras disciplinas, carga horária maior ou menor podem revelar determinações históricas e políticas ${ }^{2}$. Logo, podemos conceber mesmo a incipiente carga horária destinada explicitamente à pesquisa como um implemento ao seu ensino e presença nos cursos citados.

O envolvimento dos alunos ainda na fase de graduação em procedimentos sistemáticos de produção do conhecimento científico, familiarizando-se com as práticas teóricas e empíricas da pesquisa, é o caminho mais adequado, inclusive para alcançar os objetivos da própria aprendizagem ${ }^{23}$. Nesse contexto, é válido o complemento curricular do ensino da pesquisa também com disciplinas optativas na matriz curricular. Infelizmente, este ainda é um campo pouco explorado pelos cursos de saúde da Uece para fortalecer a pesquisa no âmbito da graduação. O curso de Enfermagem apresenta duas disciplinas optativas - Elementos Básicos de Pesquisa e Métodos Qualitativos em Enfermagem -, ambas com carga horária de 60 horas, mas é o único dos cursos pesquisados a oferecer essa complementação. O que deveria ser um acréscimo às disciplinas obrigatórias não é aproveitado em sua total potencialidade pelos demais cursos da área da saúde da Uece. A possibilidade de ensino da pesquisa por meio de disciplinas optativas, por um lado, facilita o aprofundamento dos alunos na pesquisa, mas, por outro, a dificuldade para adequarem horários e semestres de disciplinas obrigatórias com optativas parece não ser fácil. Outro fator que tem contribuído para a não realização das disciplinas optativas, embora ofertadas a cada semestre, é a exigência da Pró-Reitoria de Pós-Graduação (Prograd) de abertura de turmas com o mínimo de 12 alunos. As dificuldades dos alunos para solicitar disciplinas optativas acabam gerando a não formação de turmas, e a disciplina não pode ser ministrada, fato que já ocorreu com as disciplinas de Elementos Básicos de Pesquisa e com a de Métodos Qualitativos em Enfermagem. Entendemos, também, que os alunos ainda não se sentem despertados para a pesquisa, desconhecem o que seja e, portanto, acham-na difícil, o que dificulta sua escolha como disciplina optativa. Somente um estudo sobre as questões aqui levantadas pode trazer respostas às análises anteriormente realizadas. 
O Quadro 1 expõe a localização por semestre de cada uma das disciplinas relacionadas com o ensino da pesquisa na grade curricular dos cursos do CCS da Uece. A distribuição temporal das disciplinas é semelhante em todos os cursos e segue a lógica de concentrar as disciplinas introdutórias, que já caracterizamos posteriormente, nos semestres iniciais. Por sua vez, as disciplinas que respondem pela orientação e realização de monografia são reservadas para o final do curso. A distância entre a oferta da primeira e da segunda ou terceira disciplina de pesquisa difere bastante, sobretudo nos cursos de Nutrição e Enfermagem. A pesquisa é introduzida nos primeiros semestres (primeiro semestre do curso de Nutrição e segundo semestre do curso de Enfermagem) e posteriormente no nono semestre do curso de Nutrição e no oitavo e nono do curso de Enfermagem. Esse espaço pode trazer dificuldades no processo de elaboração e desenvolvimento do trabalho monográfico, principalmente se considerarmos que no oitavo e nono semestres de Enfermagem os alunos se encontram em campo de estágio, o que dificulta ainda mais esse processo.

Estudos como o de Cassiani et al. ${ }^{22}$ consideram que os processos de apreensão dos conhecimentos e técnicas fornecidos pelas disciplinas de pesquisa podem ser mais bem sucedidos se a disciplina Metodologia da Pesquisa for ministrada nos primeiros semestres do curso de graduação, estimulando os alunos para a importância da investigação, que será reforçada nas disciplinas subsequentes ou em atividades de extensão. Logo, não deveria haver lacuna temporal entre as disciplinas, mas, sim, continuidade de aprendizado.

Harrison et al. ${ }^{24}$ embasam essa ideia ao indicarem que não é realístico esperar que os estudantes retenham o conhecimento aprendido somente em um curso/disciplina se esse aprendizado não for reforçado subsequentemente em outras experiências de aprendizagem. Neste sentido, engajar os alunos em trabalhos de investigação pode ser uma das alternativas empregadas para garantir a consolidação da aprendizagem iniciada pelos alunos nos cursos introdutórios de metodologia científica e, mais que isso, fazer presentes os métodos de pesquisa e o perfil investigativo nas demais disciplinas do curso e não somente nas disciplinas obrigatórias de pesquisa. Tal aprendizado deverá se consolidar nos semestres posteriores, terminando com o trabalho de monografia.

A criação das disciplinas de monografia e sua introdução nos últimos semestres dos cursos de graduação já foram abordadas por Guimarães et al. ${ }^{25}$, que propuseram a transformação do caráter teórico da disciplina metodologia da pesquisa para teórico-prático mediante o implemento da pesquisa de campo como estratégia de ensino. Para tanto, os alunos inicialmente formulariam os projetos de pesquisa e depois os aplicariam em um trabalho de campo, procedendo ao levantamento de dados de situações concretas, analisando, interpretando os dados levantados e elaborando conclusões. A avaliação da disciplina não constaria de provas teóricas, mas seria baseada na análise do relatório científico, na sua apresentação e no engajamento dos alunos em todas as fases da pesquisa. Observamos que todos os cursos de graduação da área de saúde da Uece exigem a elaboração de um trabalho monográfico e sua apresentação para conclusão do curso, orientado por docentes (Quadro 3). Isto talvez possa se aproximar da proposta de Guimarães, que data de 1985, revelando uma preocupação antiga com o ensino da pesquisa nas produções científicas, posta à prova apenas mais recentemente.

Se extrapolarmos a proposta do $\operatorname{Promed}^{26}$ (p. 8) e sua classificação em estágios de transformação em relação ao seu eixo B (Abordagem Pedagógica), objeto de análise do nosso estudo, para todos os cursos de saúde da Uece, poderíamos alocálos no Estágio 2: "ensino que inclui inovações pedagógicas em caráter experimental restritas a certas disciplinas [...] ainda restritas a menos de $20 \%$ da carga horária".

De forma geral, os cinco cursos da área da saúde da Uece apresentam um número satisfatório de disciplinas e carga horária relativa ao ensino direto da pesquisa. $\mathrm{O}$ curso de Medicina, que se encontra abaixo do perfil dos demais cursos do CCS da Uece quanto ao número de disciplinas relacionadas à pesquisa ofertadas, apresenta a segunda maior carga horária absoluta por disciplina obrigatória individual.

Quadro 2

Carga horária total e número de disciplinas obrigatórias relacionadas à pesquisa nos cursos de graduação do CCS da Uece (julho de 2007)

\begin{tabular}{|c|c|c|c|}
\hline Curso & $\begin{array}{c}\text { Número de } \\
\text { disciplinas } \\
\text { obrigatórias }\end{array}$ & $\begin{array}{c}\text { Carga horária total } \\
\text { (disciplinas de } \\
\text { pesquisa })\end{array}$ & $\begin{array}{c}\text { Carga } \\
\text { horária total } \\
\text { do curso }\end{array}$ \\
\hline Enfermagem & 3 & $120 \mathrm{~h}(2,8 \%$ do total $)$ & $4.230 \mathrm{~h}$ \\
\hline Educação Física & 4 & $240 \mathrm{~h}(8,2 \%$ do total $)$ & $2.910 \mathrm{~h}$ \\
\hline $\begin{array}{c}\text { Ciências } \\
\text { Biológicas }\end{array}$ & 3 & $240 \mathrm{~h}(6,9 \%$ do total $)$ & $3.450 \mathrm{~h}$ \\
\hline Nutrição & 2 & $60 \mathrm{~h}(1,5 \%$ do total $)$ & $4.020 \mathrm{~h}$ \\
\hline Medicina & 1 & $72 \mathrm{~h}(1 \%$ do total $)$ & $6.984 \mathrm{~h}$ \\
\hline
\end{tabular}

Por outro lado, por haver apenas uma disciplina ao longo de todo o curso, os alunos recebem todo o conteúdo relacionado à pesquisa concentrado em um único momento, o que, segundo Severino ${ }^{23}$, não é muito produtivo. Isto porque se desconsidera o fato de que a formação humana é também um 
processo histórico, em que um estágio prático alcançado serve de base para alcançar o próximo. Sendo assim, o curso de Medicina queima etapas, o que compromete a qualidade do ensino da pesquisa, que é ofertada de uma só vez aos alunos e dificulta o preparo para uma formação crítico-reflexiva que o ensino da pesquisa promove. A falta de continuidade de uma aprendizagem que deveria ocorrer de maneira gradual e permanente dificulta a formação de um sujeito crítico-reflexivo. Constatamos, assim, uma diferença significativa entre o curso de Medicina e os demais cursos estudados, principalmente o de Educação Física, em termos do número de disciplinas ofertadas ao longo do curso, suas divisões por semestres e carga horária (Quadro 2).

\section{Quadro 3}

Ano de criação do curso, da disciplina de monografia e presença da exigência da monografia para conclusão dos cursos do CCS da Uece (julho de 2007)

\begin{tabular}{|c|c|c|c|}
\hline Curso & $\begin{array}{c}\text { Ano de } \\
\text { criação }\end{array}$ & $\begin{array}{c}\text { Ano de implantação } \\
\text { da disciplina de } \\
\text { monografia }\end{array}$ & $\begin{array}{c}\text { Exigência de } \\
\text { monografia }\end{array}$ \\
\hline Enfermagem & 1943 & 1997 & $\operatorname{sim}$ \\
\hline Educação Física & 2001 & 2001 & $\operatorname{sim}$ \\
\hline Nutrição & 1977 & 1999 & $\operatorname{sim}$ \\
\hline Medicina & 2003 & - & $\operatorname{sim}$ \\
\hline Ciências Biológicas & 1998 & 1998 & $\operatorname{sim}$ \\
\hline
\end{tabular}

Com as exigências trazidas pela LBD/96 e pelas Diretrizes Curriculares Nacionais, posteriormente contempladas nas diretrizes específicas de cada curso, a efetivação do ensino para os alunos de graduação mediante práticas de construção do conhecimento pautadas na pesquisa só tem aumentado nos últimos tempos, como podemos observar ao mesclar as informações contidas no Quadro 3: após a aprovação e publicação desses documentos, iniciou-se a implantação das disciplinas de monografia nos cursos estudados.

Cabe também ressaltar a relevância e validade da exigência dos Trabalhos de Conclusão de Curso (TCC), porque, apesar de suas limitações, já representam uma forma de envolver os alunos nos procedimentos concretos da pesquisa científica relacionando teoria e prática, ensino e pesquisa, e fortalecendo a formação do sujeito reflexivo ${ }^{6}$. Além de eventual contribuição de seus conteúdos, esses trabalhos serão válidos exercícios da prática da pesquisa ${ }^{23}$. O aprender a aprender ${ }^{12}$ encontra ancoragem no exercício da pesquisa, na sua vivência, na sua paixão, que deve ser despertada nos alunos, se possível, se não ainda nas escolas, pelo menos desde o início dos cursos de graduação.

O curso de Medicina, apesar de exigir um trabalho de monografia para conclusão dos estudos de graduação, diferentemente de todos os demais, não o faz pautado em uma disciplina de monografia. Os alunos de Medicina da Uece devem elaborar e apresentar seus trabalhos de conclusão de curso no $12^{\circ}$ semestre da graduação, durante o período do internato, sem o devido amparo disciplinar e com os conhecimentos adquiridos somente durante o primeiro semestre do curso. Com apenas esses mecanismos de ensino e com base no exposto até então, as chances de aprendizado dos conteúdos de pesquisa para os alunos de Medicina são, no mínimo, mais complicadas.

Tais discrepâncias não podem ser explicadas com base na recente criação do curso de Medicina, que teve sua primeira turma iniciada no primeiro semestre de 2004, uma vez que o curso de Educação Física teve sua primeira turma iniciada no primeiro semestre de 2002 e oferece outra realidade com relação ao ensino da pesquisa e à sua realização. Acreditamos que tal realidade se deva ao modelo de formação profissional adotado pelo curso de Medicina que, aparentemente, prioriza o ensino instrumental e técnico em detrimento da pesquisa. Seu PPP, embora traga a pesquisa como uma das habilidades presentes no perfil de seus egressos (Projeto Político-Pedagógico do Curso de Medicina da Uece, 2004, p.13), não apresenta propostas ou uma estrutura de matriz curricular que permita concretizar a articulação entre ensino e pesquisa.

O que podemos constatar nos cursos de saúde da Uece é uma evolução positiva em relação à pesquisa, mas uma evolução ainda lenta e limitada, com cursos mais envolvidos nesse processo (Ciências Biológicas, Educação Física e Enfermagem) e outros menos (Medicina e Nutrição). Entendemos que a implantação da monografia e a estruturação de disciplinas voltadas à pesquisa não são o suficiente para articulá-la ao currículo como um todo, perpassando de forma transversal pelas demais disciplinas e conteúdos curriculares destes cursos, análise que parte da nossa concepção de pesquisa como princípio de formação e não apenas como princípio científico. Os projetos político-pedagógicos ainda não conseguem concretizar propostas de formação e atuação que tomem a prática como objeto de reflexão e produção de conhecimento. Não se observa nos documentos uma real estrutura interdisciplinar que permeie o caráter científico de maneira uniforme dentro das matrizes curriculares de cada curso pesquisado.

\section{CONSIDERAÇÕES FINAIS}

A interação ensino/pesquisa, tomando a prática como objeto de reflexão e investigação no contexto da construção 
ativa do conhecimento, estrutura situações que conduzem os alunos a vivenciarem, como autores, a atividade de pesquisar e produzir ciência. Esse processo possibilita não apenas projetar estudos na lógica da relação ensino-pesquisa, mas também aprofundar temáticas relacionadas a outras disciplinas do curso, quando a pesquisa pode ser entendida como princípio formativo que deve estar presente como um dos eixos da grade curricular. Porém, sabemos que não podemos considerar o documento curricular oficial escrito como o único representante das intenções do que será efetivamente trabalhado no curso, dada a importância da vivência em sala de aula e nos espaços de prática, o que caracteriza os currículos paralelo e oculto ${ }^{27}$. Desta forma, reconhecemos que a vivência da pesquisa pode ser obtida pelos alunos mesmo em cursos que não a possuem na estrutura de seu eixo curricular, ficando, nestes casos, limitada à parcela dos discentes que a buscam voluntária e independentemente. Discutimos aqui a importância da oferta da pesquisa para todos os estudantes, a fim de acrescentar às suas formações uma visão crítico-reflexiva.

Constatamos a existência da pesquisa como item presente na estrutura dos PPPs dos cinco cursos do CCS da Uece, expressa concretamente em suas matrizes curriculares, porém não evidenciamos sua significativa integração ao processo de ensino ao longo das disciplinas dos cursos estudados. Tal constatação denota, entretanto, uma contribuição no sentido da formação para a reflexão-na-ação.

Notamos ser preciso um acompanhamento permanente dos Projetos Político-Pedagógicos e sua constante avaliação e reestruturação, quando necessária. Além do ensino da metodologia científica no currículo de graduação, são necessárias outras atividades científicas, a fim de incorporar a atividade de pesquisa no ensino, como: inclusão de revisão de literatura ou artigos científicos em outras disciplinas que não apenas as disciplinas de pesquisa, iniciando pelas pesquisas de natureza bibliográfica e documental; estímulo à identificação de questionamentos ligados à prática da Enfermagem, Medicina, Nutrição, Educação Física e Ciências Biológicas; discussões embasadas em resultados de investigações de professores e alunos em grupos de estudos e/ou de pesquisa; participação em conferências e/ou congressos nos quais os estudantes podem apresentar trabalhos; e envolvimento dos alunos em projetos de pesquisa dos docentes: ações concretas para o incentivo à pesquisa.

A visão de pesquisa como processo que perpassa as disciplinas do currículo proposto e que não permanece fechada em uma ou mais disciplinas específicas de pesquisa é uma concepção ainda distante da nossa realidade acadêmica em nível de graduação. É importante registrar, contudo, que a criação dos grupos de pesquisa, a contribuição das agências de fomento e a existência de universidades com bolsas para iniciação científica de alunos em nível de graduação têm sido um marco de inclusão da pesquisa na formação desde os cursos de graduação. A participação dos alunos nas semanas universitárias, em encontros de seus centros acadêmicos, em seus grupos de pesquisa é um caminho para socializar a produção e compartilhar experiências na produção de trabalhos científicos e no desenvolvimento de uma postura investigativa por parte do aluno. Esse avanço, entretanto, ainda atinge uma pequena parcela do corpo discente.

Entendemos também que experiências e análises teóricas inspiradas nos pressupostos de uma pedagogia na qual ensino e pesquisa interajam ao longo da formação profissional precisam ser partilhadas entre professores e seus pares, e entre docentes e discentes, viabilizando a produção de um conhecimento que fortaleça o caminho da mudança, contribuindo para construir um ensino que rompa com o modelo tradicional, tendo a consciência de que a transformação não é um fim a alcançar, mas um caminho a percorrer. Vemos a capacitação contínua do corpo docente, em sua maioria sem a devida formação pedagógica, como medida imprescindível à implantação de um novo modelo educacional. Neste sentido, tomamos o Projeto Cinaem ${ }^{28}$ com seu módulo de trabalho da docência médica como um exemplo a ser difundido entre as demais categorias profissionais da área da saúde.

No texto dos PPPs, DCNs e Pró-Saúde, observamos uma grande preocupação com a adequação dos futuros profissionais de saúde aos princípios do SUS, em particular no que tange à prática profissional, o que tem conduzido as mudanças curriculares numa perspectiva ainda tecnicista. Essas propostas se voltam à promoção de metodologias de ensino centradas no aluno, na resolução de problemas (Aprendizagem Baseada em Problemas - ABP). Tendem, porém, a desenvolver experiências copiadas, sem reflexão crítica, e não conseguem problematizar a organização do currículo no contexto da sociedade contemporânea, nem discutir demandas econômicas, políticas ou questões ideológicas envolvidas na formulação desses currículos ${ }^{29}$

Reconhecemos o valor e a representatividade da ABP em romper com as formas tradicionais de ensino-aprendizagem, contudo julgamos mais condizente com nossa proposta de ensino com pesquisa a adoção da problematização como metodologia de ensino. A problematização, manifestação do construtivismo na educação, tem como eixo básico a relação ação-reflexão-ação e se apoia nos fundamentos da pedagogia crítica.

Destacando-se os pontos centrais que constituem desafios e que também representam perspectivas a serem consideradas para a continuidade e aprofundamento desta discussão, 
diferentes aspectos ressaltados nos resultados deste trabalho podem suscitar outras contribuições para ampliar e acelerar o debate em torno desta mudança na formação em saúde.

A análise dos PPPs propiciou uma primeira visão do pretendido. A pesquisa existe, está registrada e é exigida nos currículos, inclusive como requisito para a graduação do aluno em qualquer dos cinco cursos de saúde pesquisados. $\mathrm{O}$ estudo em questão, contudo, ainda é limitado para referir como essas exigências se desenvolvem na prática ou se concretizam no chão da sala de aula. A dinâmica dessa formação remete, portanto, a outro tipo de estudo mais pontual, que exige, segundo acreditamos, observações nos espaços onde a pesquisa é ensinada e realizada, para que se possa identificar, dos documentos pesquisados (Diretrizes Curriculares, PPPs e ementas das disciplinas de pesquisa dos cursos estudados), o que realmente se efetiva na prática de sala de aula e como tal dinâmica se desenvolve.

\section{REFERÊNCIAS}

1. Brasil. Ministério da Educação e do Desporto. Lei no 9.394, de 20 de dezembro de 1996. Estabelece as Diretrizes e Bases da educação nacional. Diário Oficial da União. Brasília, 23 dez. 1996; Seção 3, p.27833. [acesso em 2 out. 2006]. Disponível em: https://www.planalto.gov.br/ccivil_03/ Leis/L9394.htm

2. Pinto LAM, Rangel M. Projeto Político Pedagógico da Escola Médica. Rev Bras Educ Med. 2004;28(3):251-8.

3. Barbosa FS. Explicando a integração docente assistencial no contexto de mudanças da escola médica. Rev Bras Educ Med. 1985;9:105-11.

4. Matos OCF. A indústria cultural e a imaginação estética In: Guimarães VS, org. Formar para o mercado ou para a autonomia. Campinas: Papirus; 2006.

5. Dowbor L. Educação, tecnologia e desenvolvimento. In: Ferretti JC et al. orgs. Novas tecnologias, trabalho e educação: um debate multidisciplinar. Petrópolis: Vozes; 1994.

6. Schon D. Educando o profissional reflexivo: um novo design para o ensino o ensino e a aprendizagem. Porto Alegre: Artes Médicas; 2000.

7. Gonçalves EL. Processo educacional: a interação professoraluno. Ponto e Vírgula: Bol. FMUSP 1986; 4.

8. Pontes AL, Rego S, Silva AGJ. Saber e prática docente na transformação do ensino médico. Rev Bras Educ Med. 2006;30(2):66-75.

9. Pimenta SG, Ghedin E, org. Professor reflexivo no Brasil. Cortez: São Paulo; 2002.

10. Demo P. Educar pela pesquisa. $2^{a}$ ed. Campinas: Autores Associados; 1997
11. Faria JIL, CASAGRANDE LDR. A educação para o século XXI e a formação do professor reflexivo na enfermagem. Rev Lat Am Enfermagem. 2004;5:821-7.

12. Boufleuer JP. Pedagogia da ação comunicativa. $3^{\underline{a}}$ ed. Ijuí: Unijuí; 2001.

13. Therrien J. Uma abordagem para o estudo do saber de experiência das práticas educativas. Cadernos da Pós-Graduação em Educação. 1996;5:1-4.

14. Tardif M. Saberes docentes e formação profissional. Petrópolis: Vozes; 2002.

15. Resoluções. Encontro Nacional de Entidades Médicas; 6-8 jun. 2007; Brasília, DF.

16. Almeida M, org. Diretrizes Curriculares Nacionais para os Cursos Universitários da Área da Saúde. Londrina: Rede Unida; 2003.

17. Brasil. Ministério da Saúde. Pró-Saúde-Programa Nacional de Reorientação da Formação Profissional em Saúde. [on-line] Brasília: Ministério da Saúde; 2005. [acesso em 2 out. 2006]. Disponível em: http://www.prosaude.org/ leg/index.php.

18. Demo P. Pesquisa: principio científico e educativo. $6^{\underline{a}}$ ed. São Paulo:Cortez; 1999.

19. Dencker AFM. Pesquisa e interdisciplinaridade no ensino superior: uma experiência no curso de turismo. São Paulo: Aleph; 2002.

20. Luckesi CC, Barreto E, Cosma J, Baptista N. Fazer Universidade: uma proposta metodológica. $7^{\mathrm{a}} \mathrm{ed}$. Cortez: São Paulo; 1995.

21. Hitchcock MA, Mylona ZH. Teaching faculty to conduct problem-based learning. Teach Learn Med. 2000;12(1): 52-7.

22. Cassiani SHB, Rodrigues LP. The teaching of scientific methodology in eight nursing schools of the Southeast Region (of Brazil).. Rev Lat Am Enfermagem. 1998;6(2):73-81.

23. Severino AJ. Ensino da metodologia da pesquisa científica: justificativa, fundamentação e estratégias. Fortaleza: Universidade de Fortaleza; 1999.

24. Harrison LL, Loweur B, Bailey P. Changes in nursing students' knowledge about and attitudes toward research following na undergraduate research course. J Adv Nurs. 1991;16(7):807-12.

25. Guimarães BMA, Morosini MC, Pinto AMB, Sturn A. Subsídios para um programa de treinamento de pesquisadores universitários. Rev Gauch Enferm. 1985;1: 55-61.

26. Brasil. Ministério da Saúde. Programa de Incentivo às Mudanças Curriculares para as Escolas Médicas. Brasília: Ministério da Saúde; 2002.

27. Lampert JB. Currículo de graduação e o contexto da formação do médico. Rev Bras Educ Med, 2001;25(1):7-19. 
28. Comissão Interinstitucional Nacional de Avaliação do Ensino Médico. Avaliação do ensino médico no Brasil: relatório geral 1991-1997. [s.n]: CINAEM; 1997.

29. Cyrino EG, Toralles-Pereira ML. Trabalhando com estratégias de ensino-aprendizado por descoberta na área da saúde: a problematização e a aprendizagem baseada em problemas. Cad. Saúde Pública. 2004;20(3):780-8.

\section{CONTRIBUIÇÃO DOS AUTORES}

Sílvia Maria Nóbrega-Therrien participou na concepção e desenho deste estudo, contribuindo na busca de dados e orientando a análise e interpretação dos dados assim como a redação deste texto, re-elaborei a versão final deste artigo. Laura Martins Feitosa, participou na concepção e desenho deste estudo sob orientação, realizei a busca de dados, sua análise e interpretação, redigiu a versão inicial deste texto e re-elaborei a versão final deste artigo.

\section{CONFLITO DE INTERESSES}

Declarou não haver.

\section{ENDEREÇO PARA CORRESPONDÊNCIA}

Sílvia Maria Nóbrega-Therrien

Rua Andrade Furtado, 1755 - apt ${ }^{\mathrm{o}} 401$

Papicu - Fortaleza

CEP 60190-070 - CE

E-mail: silnth@terra.com.br 